\title{
Correction to: Network-Strengthened Ti-6Al-4V/(TiC+TiB) Composites: Powder Metallurgy Processing and Enhanced Tensile Properties at Elevated Temperatures
}

\author{
SHAOLOU WEI, LUJUN HUANG, XINTING LI, YANG JIAO, WEI REN, \\ and LIN GENG
}

https://doi.org/10.1007/s11661-019-05606-1

(C) The Minerals, Metals \& Materials Society and ASM International 2019

\section{Correction to: Metallurgical and Materials Transactions A Volume 50A, August 2019}

https://doi.org/10.1007/s11661-019-05244-7

IN the original article, there is an error in Figure 1. The unit of Specific strength should be $\mathrm{MPa} /\left(\mathrm{g} \cdot \mathrm{cm}^{-3}\right)$. Following is the corrected Figure 1.

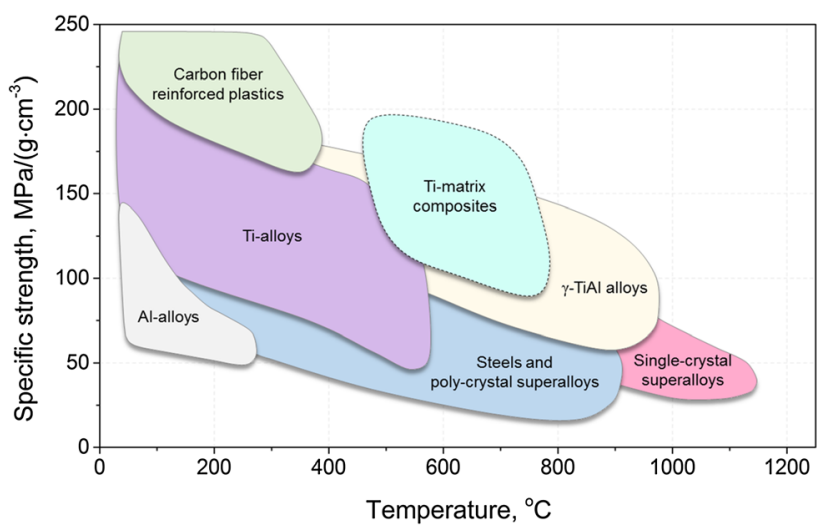

Fig. 1-Specific strength $v s$ service temperature for typical structural materials (data excerpted from References 24 and 25).

SHAOLOU WEI is with the School of Materials Science and Engineering, Harbin Institute of Technology, Harbin 150001, P.R. China and also with the Department of Materials Science and Engineering, Massachusetts Institute of Technology, Cambridge, MA. LUJUN HUANG, XINTING LI, YANG JIAO, WEI REN, and LIN GENG are with the School of Materials Science and Engineering, Harbin Institute of Technology. Contact e-mails: huanglujun@hit.edu.cn; genglin@hit.edu.cn

The original article can be found online at https://doi.org/10.1007/ s11661-019-05244-7.

Article published online December 23, 2019
On page 3636 of the original article, the orientation relationship between TiB and $\alpha$-Ti should be corrected to $(201)_{\mathrm{TiB}}\left\|(\overline{1} 110)_{\alpha-\mathrm{Ti}},[11 \overline{2}]_{\mathrm{TiB}}\right\|[0001]_{\alpha-\mathrm{Ti}}$

Publisher's Note Springer Nature remains neutral with regard to jurisdictional claims in published maps and institutional affiliations. 